Ablative therapies of renal tumors are steadily gaining popularity in clinical practice due to the many benefits they offer to patients. Moreover, ablative procedures hold promise in the field of uro-oncology for the best compromise between low invasiveness, high efficacy and advantages in terms of procedural costs. Reported outcomes with ablative therapies for small renal tumors are excellent and without significant differences for surgical procedures based on nephron-sparing surgery. Nevertheless, these methods for treatment of small renal tumors should still be confined to carefully selected patients. This review discusses the currently used ablative techniques in urology.

Key words: renal tumors, renal carcinoma, ablative methods.

\section{Ablative therapies for small renal tumors}

\author{
Jan Adamowicz ${ }^{1}$, Jakub Tworkiewicz ${ }^{2}$, Jerzy Siekiera ${ }^{3}$, Tomasz Drewa ${ }^{2,3}$ \\ 1Department Tissue Engineering, Faculty of Medicine, Ludwik Rydygier \\ Collegium Medicum in Bydgoszcz, Nicolaus Copernicus University, Torun, Poland \\ 2Department of Urology, Institute of Oncology, Bydgoszcz Poland \\ ${ }^{3}$ Department of Urology, Nicolaus Copernicus Hospital Batory, Torun, Poland
}

\section{Introduction}

Approximately 3650 new cases of renal cell cancer are reported in Poland each year. This number increases annually by $2.5 \%$ [1]. The widespread uses of radiological imaging increased the number of incidentally detected renal tumors in asymptomatic patients. The number of performed computed tomography scans increases every year by $10 \%$ [2]. High frequency of small renal tumors detection is also associated with wide accessibility to ultrasonography, which has become the initial imaging technique during the diagnostic process in urology. About $40 \%$ of detected renal tumors are clinically silent [3]. $45 \%$ of these tumors are renal cell carcinoma (RCC) in stage T1NOMO, characterized by favorable prognosis after radical surgical treatment [4]. Retrospective studies have proved that the application of nephron-sparing surgery (NSS) for these patients is as effective as radical nephrectomy. The use of NSS techniques in small tumors is highly recommended in all patients due to increased risk of development of chronic renal disease after radical nephrectomy [5, 6]. However, taking into account the increasing incidence of kidney cancer, partial nephrectomy has become an inconvenient method of treatment. The main disadvantages of partial nephrectomy are the long learning curve, duration of surgery and high costs of the procedure. Ablative treatment is an alternative method which can successfully replace partial nephrectomy in many cases.

\section{Indications for ablative therapy}

Ablative techniques are also recommended for removal of renal tumors in patients with von Hippel-Lindau syndrome and with one active kidney [7]. The most commonly used ablative techniques in urology are cryoablation and radiofrequency ablation (RFA). The next generation ablative techniques utilizing microwaves and ultrasound for tissue necrosis are under clinical trials [8]. According to EAU (European Association of Urology) guidelines, renal tumors smaller than $4 \mathrm{~cm}$ (T1a) are the only suitable indication for ablative therapy. The primary factors for further eligibility of patients are the favorable localization of the lesion and the number of tumors. Tissue ablation is usually appropriate for patients with only a few small tumors. The secondary indications are age and life expectancy after surgery. Given the controversial radicality of ablation therapies this treatment should be offered to patients with life expectancy less than 10 years. There is a need for long-term follow-up to compare the recurrence rate in patients after ablation and partial nephrectomy. Results of this experiment should give a definitive answer to the question of the effectiveness of the use of ablation in young patients and establish the place of ablative techniques in the therapeutic process. Currently there are few studies with follow-up longer than 24 months. This is particularly important taking into account the tendency for detection of renal tumors in young people without other diseases.

Ablation of renal tumors is mainly performed percutaneously nowadays under ultrasound, CT (computed tomography) or MRI (magnetic resonance 
imaging) imaging in short-term general anesthesia. The choice of ablation and imaging method should be adopted by a team consisting of a urologist and an invasive radiologist [9]. The outcomes of image-guided percutaneous ablation and laparoscopic ablation are similar. Nevertheless, percutaneous ablation is preferred for removing small tumors localized in the renal cortex. More deeply located lesions should be ablated by laparoscopic access which allows one to protect the ureter, blood vessels and intestinal wall from iatrogenic injury during the procedure [10]. The main advantage of laparoscopy is the possibility to take samples of pararenal fat for histopathological examination. The lack of pathological verification of the tumor type requires careful and accurate postoperative imaging of ablation lesions. CT or MRI imaging in the follow-up of patients after renal tumor ablation is recommended.

The first radiological evaluation should be done within 3 months after surgery and the second one after 9 months [11].

\section{Cryoablation}

Cryoablation is a therapeutic method based on local destruction of tissue by freezing. The first attempts to introduce cryoablation to clinical practice were described in the 1960s. These studies concerned the treatment of primary tumors of the liver. Until the 1990s only a few introductory studies were published whose authors proposed cryoablation for experimental treatment for renal tumors. In 1995, Uchida reported the first use of percutaneous renal cryoablation [12]. The main limitation was the large size of cryoprobes that made it difficult to precisely place them in the specified part of the kidney. The advances that have been made in the field of cryoablation equipment production led to the development of needle-shaped cryoprobes with a diameter of 2 millimeters. Such cryoprobes allow one to perform percutaneous surgery and are suitable to remove renal tumors. The latest cryoprobes do not exceed 1.5 millimeters.

The effectiveness of tissue destruction during cryoablation depends on the cooling rate and the number of cooling cycles. The killing of tumor cells during cryoablation is a multistage process. Cooling the normal tissue to $-20^{\circ} \mathrm{C}$ triggers apoptosis in all cells and results in their sudden death. Epithelial cells of renal tubules are killed at a temperature of $-19.6^{\circ} \mathrm{C}$. The tumor cells, especially RCC cells, are more resistant to low temperatures. Only cooling of the tumor mass to $-40^{\circ} \mathrm{C}$ guarantees the death of all cancer cells [13]. The nature and extent of cell damage depends on the cooling rate. The cooling rate of tissue in the range of $10^{\circ} \mathrm{C} / \mathrm{h}$ results in water crystallization in the extracellular space. Ice crystals disrupt the cell membrane and increase at the same time the extracellular osmolarity. Cooling at a rate of $100^{\circ} \mathrm{C} / \mathrm{h}$ initiates water crystallization in the cell cytoplasm. Intracellular ice crystals damage the organelles and intracellular compartments. The latest devices for cryoablation allow one to cool the tissue at the rate of $50^{\circ} \mathrm{C}$ per hour [14]. Apart from mechanical injury caused by ice crystals, the devastating effect of low temperature on tumor tissue is a consequence of damage to endothelium of blood vessels. This leads to abnormal tumor tissue perfusion and in turn extends the area of necrosis. Additionally, even a small decrease of temperature triggers activation of heat shock pro- tein, which may initiate apoptosis. These factors are responsible for enlarged tissue necrosis beyond the freezing area [14]. The area of frozen tissue depends on the size of the cryoprobe, the probe core temperature and the degree of tissue vascularization. The core probe reaches $-150^{\circ} \mathrm{C}$ in about 2$3 \mathrm{~min}$. The temperature increases gradually to $0^{\circ} \mathrm{C}$ in the tissue surrounding the cryoprobe. The formed ice ball has an average temperature of $-50^{\circ} \mathrm{C}$; this is sufficient to freeze a tumor and initiate necrosis. Some researchers suggest using higher temperatures of $-30^{\circ} \mathrm{C}$ to $-40^{\circ} \mathrm{C}$ in order to reduce the risk of bowel or ureter injury [15]. The correct placement of the cryoprobe allows one to obtain at least 5 millimeters of tissue margin around the tumor, which is frozen up to $-20^{\circ} \mathrm{C}$. Cryoablation is recommended for treating renal tumors of up to $3 \mathrm{~cm}$. The state of art is to perform double-cycle freezing with ultrasound evaluation of $1 \mathrm{~cm}$ area from the tumor's borders [16]. Davol et al. followed up 48 patients after laparoscopic cryoablation for 36-110 months (median $\sim 5$ years). Cancerfree survival was in this study $87.5 \%$. A local cancer recurrence required repeat of the procedure and was successful in $97.5 \%$ [17]. According to published data, attempts are being made to remove larger tumors than $4 \mathrm{~cm}$ using cryoablation. Renal tumors more advanced than stage T1a are characterized by irregular shape and they require more than one cryoprobe to freeze them. Nevertheless, using cryoablation in these cases is not a recommended approach.

\section{Radiofrequency ablation}

In 1997, Zlotta et al. first described the use of radiofrequency ablation (RFA) to treat renal tumors in three patients [18]. Mc Govern and colleagues first performed ultrasoundguided RFA of a renal tumor [19]. Currently, RFA is used as a routine method of ablation in many centers and it is mainly done percutaneously under ultrasound as well as CT or MRI imaging. The concept of this technique is passing a high-frequency (460-500 kHz) alternating electrical current through the tissue surrounding an electrode. The electrical resistance of tissue causes its heating up during current flow. The passing current generates heat proportional to the current density; therefore the highest temperature is generated in the tissues adjacent to the electrode. The deadly temperature for tumor cells is about $50^{\circ} \mathrm{C}$. The death of cells is a result of protein denaturation and damage of the cell membrane by high temperature. Radiofrequency ablation causes the development of coagulative necrosis within 24 hours after the procedure. The necrotic area undergoes fibrosis in the next 2-3 weeks [20] (Fig. 1). The requirement for successful ablation using RFA is to obtain a temperature of $50-100^{\circ} \mathrm{C}$ throughout the tumor and maintain it for 3-5 min. In modern devices the temperature in the area surrounding the probe is monitored to avoid exceeding $100^{\circ} \mathrm{C}$. Temperature higher than $100^{\circ} \mathrm{C}$ results in tissue vaporization and charring. It reduces the effectiveness of ablation, because there is no circuit between the probe and the ground. Generally, all devices must generate $200 \mathrm{~W}$ of power to perform successful ablation. A single probe is used for the removal of tumors smaller than $2 \mathrm{~cm}$. Several probes or a single probe with branches like an umbrella needs to be used in cases of renal tumors of size greater than $2 \mathrm{~cm}$ [21]. The use of RFA is rec- 


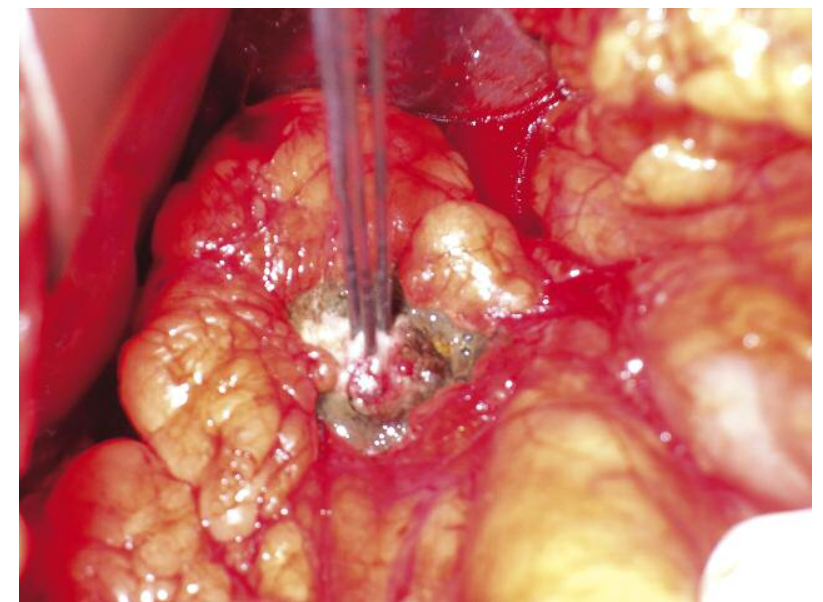

Fig. 1. Thermoablation of renal tumor, using a probe with multiple tines (open method)

ommended for tumors less than $4 \mathrm{~cm}$. Varkarakis et al. reported that lesion size influences the efficacy of RFA. In patients with renal tumors less than $3 \mathrm{~cm}$ local recurrence was not observed in any case. On the other hand, in patients with tumors larger than $4 \mathrm{~cm}$ the efficacy of therapy decreased to $80 \%$ [22]. Gervais et al. did not report any local recurrence in 100 patients after RFA renal tumors smaller than $4 \mathrm{~cm}$. The average follow-up in studies concerning clinical use of ablative methods is 2.5 years (Fig. 2) [23].

Localization of tumor is another crucial factor that has an impact on ablation effectiveness.

Lesions situated within the renal cortex are the most suitable for treatment with RFA.

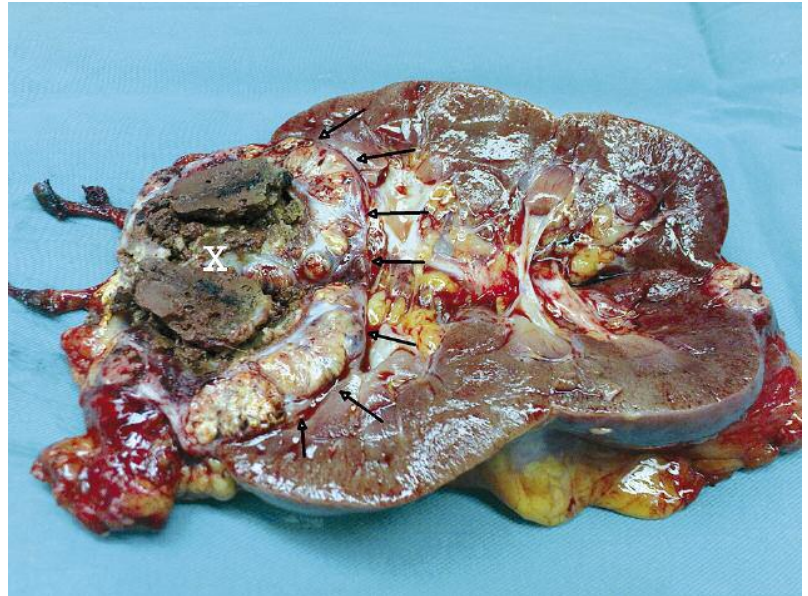

Fig. 2. State after unsuccessful RFA removal of renal mass. The recurrence at the edge of the area treated with thermoablation (X). The arrows indicate the place of recurrence

The ablation of tumors adjacent to the collective system is a more challenging task. Firstly, in this case there is a high risk of accidental damage of the renal hilum vessels. Secondly, these vessels work as heat exchangers that decrease the temperature generated by the RFA probe. In overall clinical usefulness RFA is a comparable method of treatment to cryoablation. The risk of iatrogenic injury during the procedure is similar in both techniques. The main side effects are injuries of the ureter and renal hilum vessels [24]. RFA requires a highly skilled ultrasound operator to be well performed. The main challenge is to accurately place the RFA needle just in the middle of the long axis of the tumor.
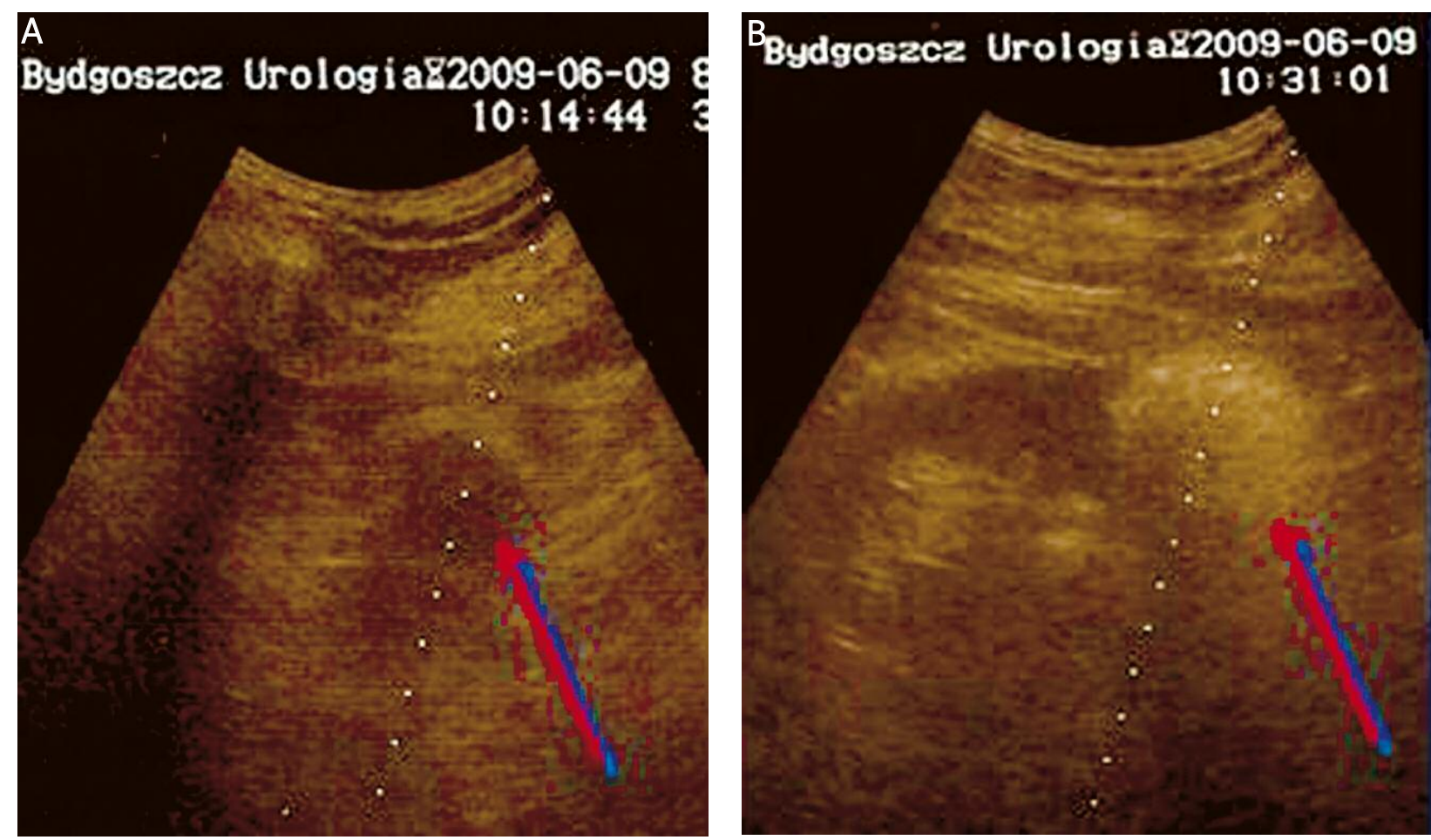

Fig. 3. Currently, most thermoablation is performed under ultrasonography. Ultrasound is also used to take a biopsy specimen from a lesion. The renal mass before thermoablation (picture A). The same tumor after thermoablation (picture B) 


\section{High-intensity focused ultrasound}

Percutaneous application of high-intensity focused ultrasound (HIFU) is an attractive method to treat small renal tumors. The HIFU procedure is image guided using MRI or ultrasound to target the ultrasound beam on the tumor in the most optimum way. HIFU is a completely non-invasive procedure for patients. During HIFU therapy the ultrasound generator moves over the patient's skin under computer control. The high-energy ultrasound waves are generated by a cylindrical piezoceramic element with a parabolic reflector. The computer automatically integrates data from the imaging device with the movements of the robotic arm where the ultrasound generator is situated, to precisely focus the ultrasound beam on the tumor and deposit specific energy within it. The temperature rises due to energy deposition up to $80^{\circ} \mathrm{C}$ and causes coagulation necrosis. Additionally, the ultrasound waves induce vibration and tear the cytoplasmic membrane. Hacker et al. investigated the effect of HIFU on healthy renal tissue. He observed interstitial hemorrhages, fiber rupture, shrinkage of collagen fibers and coagulation necrosis [25]. In clinical practice the risk of accidental damage to healthy tissue is very low due to use of effective imaging guidance methods. Currently HIFU therapy for renal tumors is under clinical trials but it is gaining popularity very fast and in many centers HIFU is already used routinely. Kormann et al. published the results of ablating three tumors in one kidney by HIFU. In this case, two tumors in the lower pole were successfully cured, but the third one localized in the upper pole was intact because the ultrasound waves were absorbed by the ribs [26]. Marberger et al. described the use of HIFU in 16 patients. The coagulation necrosis throughout the whole renal tumor was confirmed only in 5 cases [27]. The failure of HIFU therapy against renal tumors is associated with difficulties in the appropriate setting of HIFU generator parameters. The histological heterogeneity of small renal tumors affects diffusion of the ultrasound beam in the tumor mass. The disturbances in the propagation of ultrasound waves have an impact on the effectiveness of HIFU ability to cause necrosis. The difficulties in proper energy deposition within tissue lead to side effects often observed in patients undergoing HIFU therapy. A long persistent hematuria and renal pain are most commonly observed. These symptoms are a consequence of damage of the renal structures. HIFU is an experimental method today due to the limited therapeutic success confirmed in many clinical studies. Further improvements of this method are absolutely necessary for the wide treatment of renal tumors in clinical practice.

\section{Microwave ablation}

Microwaves are emitted by the antenna which is percutaneously inserted in the tumor. It generates an alternating magnetic field which induces rotation of water molecules and thermal energy flow. Microwave ablation (MA) kills the cells in a similar mechanism as RFA does. It increases the temperature of tissue above $50^{\circ} \mathrm{C}$ and initiates coagulation necrosis. Currently, microwave ablation is an experimental method. Routinely, renal tumors are treated using microwaves only in Japan. In Japan access to new medical technologies is wider and cheaper than in Europe [28].
Nevertheless, microwave ablation is the therapy of the future. According to the results of the preliminary research, it is an equally effective method as other ablative procedures presented above; however, it is much faster and easier to perform. On the other hand, the number of studies is not sufficient to compare its efficacy to well constituted ablation techniques. The treatment of renal tumors using MA requires a single session and takes $5 \mathrm{~min}$. In comparison with RFA, the temperature obtained in MA, using the same power, is higher. Additionally, microwaves penetrate very easily through the tumor and the temperature is more equally distributed. A homogeneous electromagnetic field is generated around the probe. Thus the area of tissue necrosis is most predictable among all ablative methods. $A 4 \mathrm{~cm}$ tumor requires the application of a single percutaneous antenna [29]. Studies have shown that microwave ablation can be used effectively for small renal tumors in stage T1. Liang et al. reported 12 cases of renal tumors which were removed using microwave ablation. The follow-up was 11 months long and no recurrence was noted in any cases. Based on the results of different studies, the risk of recurrence after renal tumor ablation using microwaves is calculated at 5\% [30].

\section{References}

1. www.uroweb.org/fileadmin/tx_eauguidelines/2009/Full/RCC.pdf 2. Gervais DA, McGovern FJ, Arellano RS, McDougal WS, Mueller PR. Radiofrequency ablation of renal cell carcinoma. Part 1: Indications, results, and role in patient management over a 6-year period and ablation of 100 tumors. AJR Am J Roentgenol 2005; 185: 64-71.

3. Amis ES Jr., Butler PF, Applegate KE, et al. American College of Radiology white paper on radiation dose in medicine. J Am Coll Radiol 2007; 4: 272-84.

4. http://www.uroweb.org/fileadmin/tx_eauguidelines/2009/Full/ RCC.pdf

5. Munver R, Disick GI, Lombardo SA, Bargman VG, Sawczuk IS. Cryoablation of small renal tumors in patients with solitary kidneys: initial experience. Adv Urol 2008: 197324.

6. Carini M, Minervini A, Serni S. Nephron-sparing surgery: current developments and controversies. Eur Urol 2007; 51: 12-14.

7. Goldberg SN, Charboneau JW, Dodd GD, et al.; International Working Group on Image-Guided Tumor Ablation. Image-guided tumor ablation: proposal for standardization of terms and reporting criteria. Radiology 2003; 228: 335-45.

8. Goldberg SN, Grassi CJ, Cardella JF, et al.; Society of Interventional Radiology Technology Assessment Committee; International Working Group on Image-Guided Tumor Ablation. Image-guided tumor ablation: standardization of terminology and reporting criteria. Radiology 2005; 16: 765-78.

9. Gill IS. Minimally invasive nephron-sparing surgery. Urol Clin North Am 2003; 30: 551-79.

10. Baust JG, Gage AA. The molecular basis of cryosurgery. BJU Int 2005; 95: 1187-91.

11. Janzen NK, Kim HL, Figlin RA, Belldegrun AS. Surveillance after radical or partial nephrectomy for localized renal cell carcinoma and management of recurrent disease. Urol Clin North Am 2003; 30: 843-52.

12. Gill IS, Remer EM, Hasan WA, Strzempkowski B, Spaliviero M, Steinberg AP, Kaouk JH, Desai MM, Novick AC. Renal cryoablation: outcome at 3 years. J Urol 2005; 173: 1903-7.

13. Chosy SG, Nakada SY, Lee FT Jr, Warner TF. Monitoring renal cryosurgery: predictors of tissue necrosis in swine. J Urol 1998; 159: 1370-4.

14. Yang WI, Addona T, Nair DG, Lixin Q, Ravikumar TS. Apoptosis induced by cryo-injury in human colorectal cancer cells is associated with mitochondrial dysfunction. Int J Cancer 2003; 103: 360-9. 
15. Campbell SC, Krishnamurthi V, Chow G, Hale J, Myles J, Novick AC. Renal cryosurgery: experimental evaluation of treatment parameters. Urology 1998; 52: 29-34.

16. Woolley ML, Schulsinger DA, Durand DB, Zeltser IS, Waltzer WC. Effect of freezing parameters (freeze cycle and thaw process) on tissue destruction following renal cryoablation. J Endourol 2002; 16: 519-22.

17. Davol PE, Fulmer BR, Rukstalis DB. Long-term results of cryoablation for renal cancer and complex renal masses. Urology 2006; 68: 2-6.

18. Zlotta AR, Wildschutz T, Raviv G, Peny MO, van Gansbeke D, Noel JC, Schulman CC. Radiofrequency interstitial tumor ablation (RITA) is a possible new modality for treatment of renal cancer: ex vivo and in vivo experience. J Endourol 1997; 11: 251-8.

19. McGovern FJ, Wood BJ, Goldberg SN, Mueller PR. Radio frequency ablation of renal cell carcinoma via image guided needle electrodes. J Urol 1999; 161: 599-600.

20. Rendon RA, Gertner MR, Sherar MD, Asch MR, Kachura JR, Sweet J, Jewett MA. Development of a radiofrequency based thermal therapy technique in an in vivo porcine model for the treatment of small renal masses. J Urol 2001; 166: 292-8.

21. Rendon RA, Kachura JR, Sweet JM. The uncertainty of radio frequency treatment of renal cell carcinoma: findings at immediate and delayed nephrectomy. J Urol 2002; 167: 1587-92.

22. Varkarakis IM, Allaf ME, Inagaki T, Bhayani SB, Chan DY, Su LM, Jarrett TW, Kavoussi LR, Solomon SB. Percutaneous radio frequency ablation of renal masses: results at a 2-year mean followup. J Urol 2005; 174: 456-60.

23. Gervais DA, McGovern FJ, Arellano RS, McDougal WS, Mueller PR. Radiofrequency ablation of renal cell carcinoma: part 1, indications, results, and role in patient management over a 6-year period and ablation of 100 tumors. AJR Am J Roentgenol 2005; 185: 64-71.

24. Goel RK, Kaouk JH. Probe ablative treatment for small renal masses: cryoablation vs. radio frequency ablation. Curr Opin Urol 2008; 18: 467-73.

25. Hacker A, Mitchel MS, Marlinghause E, Kohrmann K, Alken P. Extracorporeally induced ablation of renal tissue by high-intensity focused ultrasound. BJU Int 2006; 97: 779-85.

26. Köhrmann KU, Michel MS, Gaa J, Marlinghaus E, Alken P. High intensity focused ultrasound as noninvasive therapy for multilocal renal cell carcinoma: case study and review of the literature. J Urol 2002; 167: 2397-403.

27. Marberger M, Schatzl G, Cranston D, Kennedy JE. Extracorporeal ablation of renal tumours with high-intensity focused ultrasound. BJU Int 2005; 95 (Suppl 2): 52-5.

28. Wright SA, Lee FT, Mahvi DM. Hepatic microwave ablation with mul tiple antennae results in synergistically larger zones of coagulation necrosis. Ann Surg Oncol 2003; 10: 275-83.

29. Durick NA, Laeseke PF, Broderick LS, et al. Microwave ablation with triaxial antennas tuned for lung: results in an in vivo porcine model. Radiology 2008; 247: 80-7.

30. Liang P, Wang Y, Zhang D, Yu X, Gao Y, Ni X. Ultrasound guided percutaneous microwave ablation for small renal cancer: initial experience. J Urol 2008; 180: 844-88.

\section{Address for correspondence}

\section{Jan Adamowicz}

Collegium Medicum

Karłowicza 24

85-092 Bydgoszcz, Poland

e-mail: adamowicz.jz@gmail.com

Submitted: $\quad 11.10 .2012$

Accepted: $\quad 22.01 .2012$ 